\title{
Anti-inflammatory Effects in LPS-treated RAW 264.7 Cells and the Influences on Drug Metabolizing Enzyme Activities by the Traditional Herbal Formulas, Yongdamsagan-Tang and Paljung-san
}

\author{
Hyekyung Ha, Seong Eun Jin, Chang-Seob Seo, Hyeun-kyoo Shin ${ }^{*}$ \\ KM Science Research Division, Korea Institute of Oriental Medicine
}

\begin{abstract}
Objectives: Yongdamsagan-tang (YST) and Paljung-san (PJS) in traditional medicine and finasteride in modern medicine are used to treat benign prostatic hyperplasia (BPH). In recent, the use of combination herbal remedies with conventional drugs has been increasing. Therefore, we investigated the anti-inflammatory effects of these drugs to treat $\mathrm{BPH}$ and the influence of herbal formulas on finasteride metabolism.

Methods: The inhibitory effects of the herbal formulas and finasteride on the production of inflammatory mediators and cytokines were determined in lipopolysaccharide (LPS)-treated RAW 264.7 cells. Additionally, the influence of herbal formulas on activities of human drug metabolizing enzymes (DMEs) was assessed using human microsomal enzymes.

Results: We observed that YST, PJS and finasteride inhibited the production of nitric oxide (NO), prostaglandin $\mathrm{E}_{2}$ $\left(\mathrm{PGE}_{2}\right)$ and interleukin-6 (IL-6) in RAW 264.7 cells. The half maximal inhibitory concentration $\left(\mathrm{IC}_{50}\right)$ of YST on $\mathrm{PGE}_{2}$ production was calculated to be below $25 \mu \mathrm{g} / \mathrm{mL}$. YST inhibited the activity of uridine diphosphateglucuronosyltransterase (UGT) $1 \mathrm{~A} 4$ with an $\mathrm{IC}_{50}$ value of $49.35 \mu \mathrm{g} / \mathrm{mL}$. The activities of cytochrome P450 (CYP) 1A2, CYP2B6, CYP2C19, CYP3A4, and UGT1A1 were inhibited by PJS ( $\mathrm{IC}_{50}<100 \mu \mathrm{g} / \mathrm{mL}$, each). Although PJS and YST inhibited the activities of CYP3A4 and UGT1A4, respectively, these formulas may not influence the metabolism of finasteride because the $\mathrm{IC}_{50}$ values of herbal formulas on DMEs are too high to affect metabolism. Conclusions: Our results suggest that the combination of finasteride and YST or PJS might not influence their drug metabolism and that the drugs may have synergistic effects against $\mathrm{BPH}$.
\end{abstract}

\section{Key Words : Yongdamsagan-tang, Paljung-san, Benign prostatic hyperplasia, Anti-inflammation, Drug metabolizing enzymes}

\section{Introduction}

Benign prostatic hyperplasia (BPH), an aging-related chronic disease in men, is a noncancerous increase in size of the prostate caused by hyperplasia of prostatic stromal and epithelial cells. Prostate hyperplasia results in lower urinary tract symptoms (LUTS), such as urinary frequency, urgency, nocturia, weak stream, hesitancy, intermittency, incomplete emptying and straining, because the enlarged prostate leads to urethral compression. Commonly used medications to treat $\mathrm{BPH}$ are

\footnotetext{
- Received : 28 January 2021 - Revised : 16 June 2021 - Accepted : 30 July 2021

- Correspondence to : Hyeun-kyoo Shin

Herbal Medicine Research Division, Korea Institute of Oriental Medicine

1672 Yuseong-daero, Daejeon 34054, Republic of Korea

Tel : +82-42-868-9464, Fax : +82-42-864-2120, E-mail : hkshin@kiom.re.kr
} 
classified as $\alpha$-adrenergic receptor blockers, $5-\alpha$ reductase inhibitors (5-ARIs), phosphodiesterase-5 (PDE-5) inhibitors, anticholinergic and $\beta-3$ agonists. The limitations of these medications are weak or moderate efficacy, long-term administration and side effects such as lowering of blood pressure, dizziness, and peripheral edema ${ }^{1)}$. Recently, it has been cited that not only do the combination of $\alpha$ -blocker/5-ARI, PDE-5 inhibitor/ $\alpha$-blocker, and PDE-5 inhibitor/5-ARI have additive effects compared to monotherapy in LUTS-BPH patients ${ }^{2}$, but also several herbal remedies, such as complementary and alternative medications, have a positive influence against a low degree of efficacy and short- and long-term adverse effects of conventional drugs against $\mathrm{BPH}^{3}$.

In recent years, the use of herbal remedies has been increasing as the awareness of complementary and alternative medicine (CAM) has raised due to the growing interest in health care and the therapeutic effects of conventional medicines that do not meet the expectations of patient ${ }^{4}$. Yongdamsagan-tang (YST; Long Dan Xie Gan-tang in Chinese and Ryutan-shakan-to in Japanese) and Paljung-san (PJS; Ba Zheng-san in Chinese), traditional herbal formulas, contain eleven and nine herbal medicines, respectively. YST and PJS are known to be used to treat BPH due to their 'clear heat and drain dampness' effects ${ }^{5)}$. YST has been traditionally used to treat liver and/or gallbladder-related symptoms, such as headache, hypochromic pain, dizziness, and difficult urination with pain. Recently, it has been cited that YST has not only immunomodulatory, hepatoprotective, anti-inflammatory and anti-allergic effects in non-clinical studies ${ }^{6-8)}$ but also reduction of postoperative pain and discomfort after transurethral resection of the prostate (TURP) and urination difficulty in clinical studies ${ }^{9,10)}$. Traditionally, PJS has been used to treat urinary disturbances, including urinary retention, hematuria, dysuria, delayed micturition, and residual urine sense, in men. Recently, it has been reported that PJS reduces the international prostate symptom score (IPSS) and post void residual urine (PVR) in patients with $\mathrm{BPH}^{11)}$, as well as infiltration of monocytes/macrophages and gene expression of inflammatory cytokines in the prostate of chronic nonbacterial prostatitis-induced rats ${ }^{12}$.

Chronic inflammation of the prostate is also known to be involved in the pathogenesis of BPH. In BPH patients, the prostate volume in the high-inflammation group was larger than in the low-inflammation group, and immune cell-mediated inflammation as well as stromal and epithelial cell-related inflammation were observed in the prostate $^{13)}$. $\mathrm{T}$ lymphocytes and macrophages are mainly related with inflammatory responses in the prostate with $\mathrm{BPH}^{14)}$. In a previous study, our research group has reported that YST inhibits testosterone-induced benign prostatic hyperplasia through antiproliferative and antioxidative activities in the rat prostate ${ }^{15)}$ and suppresses inflammatory response as well as cell proliferation in benign prostatic hyperplasia epithelial-1 (BPH-1) cells ${ }^{16)}$. PJS has also been reported to induce apoptosis of BPH-1 cell and to inhibit prostate hyperplasia in rats $^{17)}$. Finasteride is a 5-ARI, which inhibits conversion from testosterone to dihydrotestosterone (DHT), which mediates prostate growth.

The combined use of herbal medicines and conventional medicines is increasing with the 
expectation of a higher effect ${ }^{18-19)}$. However, no clinical studies on combination therapy of YST or PJS with finasteride have been found. In the present study, therefore, we evaluated both the anti-inflammatory activities of finasteride and two herbal formulas, YST and PJS, which have been used to treat $\mathrm{BPH}$, on a macrophage cell line, RAW 264.7 cells, and the influence of herbal formulas on the activity of human drug metabolizing enzymes to predict herb-drug interactions when herbal formulas are used in combination with the conventional medication such as finasteride.

\section{Materials \& methods}

\section{Preparation of herbal formula extracts}

The eleven and nine herbal constituents of YST and PJS (Table 1), respectively, were chopped, mixed and then extracted with 10-fold (w/v) water at $100^{\circ} \mathrm{C}$ for $2 \mathrm{~h}$ in an electric herb extractor (COSMOS-660, Kyungseo Machine Co., Incheon, Korea). All herbal constituents were identified by Professor Je Hyun Lee (Department of Herbology, College of Oriental Medicine, Dongguk University, Gyeongju, Korea) and Professor Young-Bae Seo (Department of Herbology, College of Oriental Medicine, Daejeon University, Daejeon, Korea). The voucher specimens (2012-KE49-1 11 and 2015-KE56-1 9) have been deposited at the K-herb Research Center, Korea Institute of Oriental Medicine. The extracted solutions of YST and PJS were filtered with a standard sieve (270 mesh) and lyophilized by using a freeze drier (PVT100, Ilshin Bio Base, Yangju, Korea). Yields of the powdered YST and PJS extract were $18.53 \%$ and $9.34 \%$, respectively. The phytochemical ingredients of two herbal formulas were analyzed in previous reports ${ }^{16,17)}$. The contents of phytochemical ingredients of both herbal formulas are described in Table 2.

\section{Cell culture and viability assay}

The murine macrophage cell line RAW 264.7 was obtained from the American Type Culture Collection (ATCC, Rockville, MD, USA). The cells were maintained in Dulbecco's modified Eagle's medium (DMEM, Gibco BRL, Grand Island, NY, USA) containing $5.5 \% \quad(\mathrm{v} / \mathrm{v})$ heat-inactivated fetal bovine serum (FBS, Gibco BRL), $100 \mathrm{U} / \mathrm{ml}$ penicillin (Gibco BRL) and 100 $\mu \mathrm{g} / \mathrm{mL}$ streptomycin (Gibco BRL) at $37^{\circ} \mathrm{C}$ in a humidified, $5 \% \mathrm{CO}_{2}$ atmosphere. To assay cell viability, cells $\left(3 \times 10^{3}\right.$ cells/well) were seeded in 96-well plate and incubated for $16 \mathrm{~h}$. The cells were treated with various concentrations $(0$, $6.25-400 \mu \mathrm{g} / \mathrm{mL}$ ) of herbal formula extracts. After treatment for $24 \mathrm{~h}, 10 \mu \mathrm{L}$ of Cell Counting Kit-8 reagent (CCK-8, Dojindo Lab., Kumamoto, Japan) was added to each well. After incubation with CCK-8 for $4 \mathrm{~h}$, the absorbance of each well was measured at $450 \mathrm{~nm}$ using a Benchmark Plus Microplate Reader (Bio-Rad Lab., Hercules, CA, USA) and the percentages of viable cells were calculated. Non-cytotoxic concentrations of extracts were used for subsequent assays.

\section{Quantification of inflammatory mediators and cytokines in LPS-stimulated RAW 264.7 cells}

RAW 264.7 cells were plated in 48-well plates at $2.5 \times 10^{5}$ cells/well. After resting for $16 \mathrm{~h}$, the cells were stimulated with $1 \mu \mathrm{g} / \mathrm{mL}$ lipopolysaccharide 


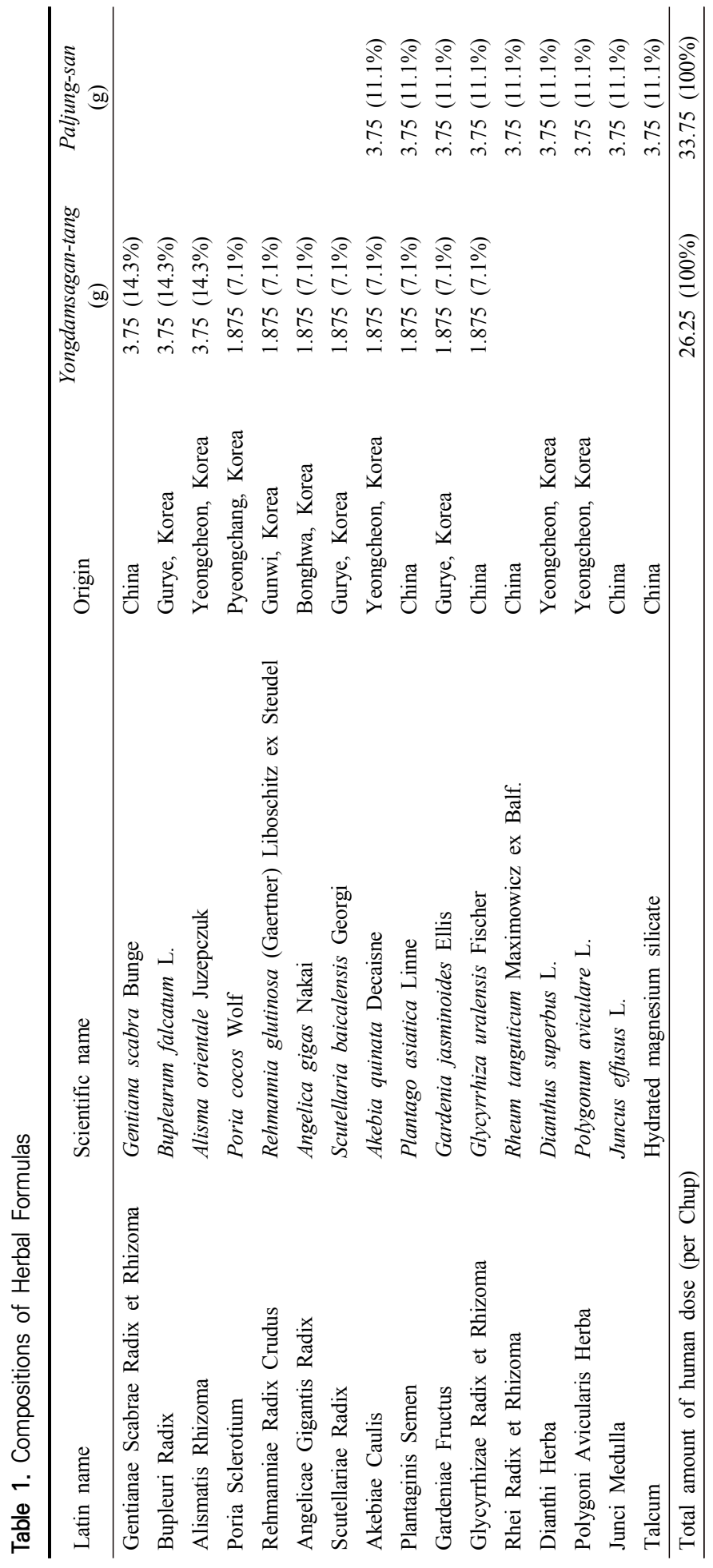


(LPS; Sigma Chemical Co., St. Louis, MO, USA) in the presence or absence of herbal formula extracts and finasteride (Sigma Chemical Co.) for $24 \mathrm{~h}$. The positive controls for nitric oxide (NO) and prostagladin $\mathrm{E}_{2}\left(\mathrm{PGE}_{2}\right)$ inhibition were $N^{G}$-methyl-L-arginine (NMMA; Sigma Chemical Co.) and indomethacin (Sigma Chemical Co.), respectively. The cultured media were collected and the levels of nitrite (as an index of NO), $\mathrm{PGE}_{2}$, interleukin-6 (IL-6) and tumor necrosis factor (TNF- $\alpha$ ) were quantified. The levels of inflammatory mediators ( $\mathrm{NO}$ and $\mathrm{PGE}_{2}$ ) and cytokines (IL-6 and TNF- $\alpha$ ) were measured by the Griess reagent system (Promega Co., Madison, WI, USA), PGE $_{2}$ enzyme-linked immunoassay (EIA) kit (Cayman Chemical Co., Ann Arbor, MI, USA) and BD OptEIATM mouse IL-6 and TNF- $\alpha$ ELISA kits (BD Bioscience, San Jose, CA, USA), respectively, according to the manufacturer's protocols. All assays were repeated at least three times.

\section{Measurement of human hepatic microsomal cytochrome P-450s (CYP450s) activities}

Vivid $^{\circledR}$ CYP450 Screening Kits (Invitrogen Co., Camarillo, CA, USA) were used to measure the activities of human hepatic CYP1A1 (Vivid $^{\circledR}$ CYP1A2 Blue), CYP2B6 (Vivid ${ }^{\circledR}$ CYP2B6 Blue), CYP2C9 $\quad$ (Vivid $^{\circledR}$ CYP2C9 Blue), CYP2C19 (Vivid $^{\circledR}$ CYP2C19 Blue), CYP2D6 (Vivid ${ }^{\circledR}$ CYP2D6 Blue), CYP2E1 (Vivid ${ }^{\circledR}$ CYP2E1 Blue) and CYP3A4 (Vivid ${ }^{\circledR}$ CYP3A4 Blue) according to the manufacturer's protocols. In brief, $40 \mu \mathrm{L}$ of $2.5 \times$ test samples and each known CYP450 isozyme inhibitors as positive controls were added into the wells of a black 96-well plate for fluorescence (Thermo Fisher Scientific, Roskilde, Denmark). $\alpha$-Naphthoflavone, sulfaphenazole, quinidine, sodium diethyldithiocarbamate trihydrate (DDC) and ketoconazole (Sigma Chemical Co.) were used as positive controls of enzyme activity inhibition for CYP1A2, CYP2C9, CYP2D6, CYP2E1 and CYP3A4, respectively. The positive control for CYP2B6 and CYP2C19 was miconazole (Sigma Chemical Co.). $50 \mu \mathrm{L}$ of Master Pre-Mix solution containing CYP450 BACULOSOMES $^{\circledR}$ Plus reagent as human microsomal P450 isozymes and $\mathrm{Vivid}^{\mathbb{B}}$ Regeneration

Table 2. The Contents of Phytochemical Ingredients in Herbal Formula Extracts

\begin{tabular}{|c|c|c|c|}
\hline \multicolumn{2}{|c|}{ Yongdamsagan-tang } & \multicolumn{2}{|c|}{ Paljung-san } \\
\hline Phytochemicals & Contents (mg/g ext.) & Phytochemicals & Contents (mg/g ext.) \\
\hline Chlorogenic acid & 1.41 & Chlorogenic acid & 2.27 \\
\hline Geniposide & 5.50 & Geniposide & 3.56 \\
\hline Liquiritin apioside & 1.85 & Liquiritin apioside & 4.23 \\
\hline Liquiritin & 1.82 & Liquiritin & 3.00 \\
\hline Glycyrrhizin & 2.69 & Glycyrrhizin & 6.78 \\
\hline Gentiopicroside & 17.89 & Gallic acid & 1.21 \\
\hline Nodakenin & 1.51 & 5-Caffeoylquinic acid & 1.18 \\
\hline Baicalein & 22.82 & Chrysophanol & 0.004 \\
\hline Wogonoside & 5.31 & & \\
\hline
\end{tabular}


System, including glucose-6-phosphate and glucose-6-phosphate dehydrogenase, in Vivid $^{\circledR}$ CYP450 Reaction Buffer was added to each well. To encourage interaction of the test samples with CYP450 isozymes in the absence of enzyme turnover, the plate was incubated with shaking for $10 \mathrm{~min}$ at room temperature (RT). The enzyme reaction was started by adding $10 \mu \mathrm{L}$ of $10 \times$ Vivid $^{\circledR}$ Substrate and Vivid ${ }^{\circledR}$ NADP $^{+}$mixture. Vivid ${ }^{\circledR}$ EOMCC for CYP1A2, CYP2C19, CYP2D6 and CYP2E1 and Vivid ${ }^{\circledR}$ BOMCC for CYP2B6, CYP2C9 and CYP3A4 were used as a Vivid ${ }^{\circledR}$ Substrate. The plate was immediately transferred into a SpectraMax ${ }^{\circledR}$ i3 multi-mode plate reader (Molecular Devices Co., Sunnyvale, CA, USA), and fluorescence intensity (FI) was subsequently measured for 60 $\min$ at excitation $(415 \mathrm{~nm})$ and emission (460 $\mathrm{nm})$ wavelengths. In the linear section of the fit to the FI and incubation time, the percent inhibition of CYP450s by test samples were calculated by the equation: $\%$ Inhibition $=(1-\Delta$ $\mathrm{T} / \Delta \mathrm{C}) \times 100 \%$, where $\Delta \mathrm{T}$ and $\Delta \mathrm{C}$ are the difference in FI before and after incubation with the test samples and the control (no inhibitor), respectively. The data are described as the means \pm standard error of the mean (SEM; $n=3)$. To calculate the $50 \%$ inhibitory concentration of the desired activity $\left(\mathrm{IC}_{50}\right)$, the inhibition curve for enzyme activity by test samples was created using a SigmaPlot software Ver. 12.5 (Systat Software, Inc., CA, USA) capable of generating a 4-parameter logistic curve-fit.

\section{Measurement of human microsomal UDP-glucuronosyltransferases (UGTs) activities}

UGT1A1 and UGT2B7 activity were evaluated by using the UGT-Glo ${ }^{\text {TM }}$ UGT1A1 and UGT2B7 Screening Systems (Promega, Madison, WI, USA), respectively, according to the manufacturer's protocols. UGT1A4 activity was measured by using the recombinant human UGT1A4 enzyme (Corning, Inc. Life Science, Tewksbury, MA, USA) as an enzyme source and the UGT-Glo ${ }^{\mathrm{TM}}$ Screening System (Promega) according to the manufacturer's protocol. The assay systems contain two glucuronidation reaction sets in parallel. An enzyme source of UGTs (UGT1A4, UGT1A1 or UGT2B7) and the proluciferin substrate (UGT1A4 specific substrate or UGT multienzyme substrate) were included both reactions. However, the uridine 5-diphosphoglucuronic acid (UDPGA) cofactor to generate the glucuronidated proluciferin was applied only in one reaction (plus-UDPGA reaction). In brief, $10 \mu \mathrm{L}$ of 4 -fold concentrated test samples, the positive controls (diclofenac (Sigma Chemical Co.) as an inhibitor of the UGT1A1 and UGT2B7 isozymes; lopinavir (Sigma Chemical Co.) as an UGT1A4 inhibitor) or vehicle ( $1 \%$ DMSO) were added to each well of white opaque 96-well plates $\left(\right.$ Costar $^{\circledR}$ Corning Inc., NY, USA). Sequentially, $10 \mu \mathrm{L}$ of $16 \mathrm{mM}$ UDPGA or distilled water was added to the desired wells for plus-UDPGA or minus-UDPGA reactions, respectively. The enzyme reactions were started by adding $20 \mu \mathrm{L}$ of $2 \times$ UGT reaction mixture containing UGT-Glo ${ }^{\mathrm{TM}}$ buffer, UGT substrate and UGT microsomes in the relevant wells. In the minus-UGT control wells, $20 \mu \mathrm{L}$ of $2 \times$ control reaction mixture containing control microsomes instead of UGT microsomes was added. The plate was incubated for 120, 90 
and $180 \mathrm{~min}$ with shaking at $37^{\circ} \mathrm{C}$, respectively, for UGT1A1, UGT2B7 and UGT1A1. After the enzyme reaction, $40 \mu \mathrm{L}$ of Luciferin Detection Reagent containing D-cysteine was added to all wells. To stabilize the luminescence signal, the plate was placed for $20 \mathrm{~min}$ at room temperature, and the luminescence intensity (LI) was later measured using a SpectraMax ${ }^{\circledR}$ i3. The percent inhibition was calculated by the following equation: $\%$ inhibition $=\left[1-\left(\mathrm{S} / \mathrm{C}_{\mathrm{AVR}}\right)\right] \times 100$, where $\mathrm{S}$ is the percent of substrate consumed (\%SC) of each test sample or the minus-UGT control wells, and $\mathrm{C}_{\mathrm{AVR}}$ is the average \% $\mathrm{SC}$ of the minus-UGT control wells. The \% $\mathrm{SC}$ was calculated by the following equation: $\% \mathrm{SC}=\Delta \mathrm{LI} / \mathrm{mLI}_{\mathrm{AVR}} \times 100$, where $\Delta \mathrm{LI}$ is the difference of background corrected LI at the minus-UDPGA reaction and the plus-UDPGA reaction for each well, and $\mathrm{mLI}_{\mathrm{AVR}}$ is the average LI of the minus-UDPGA reaction for each condition. To calculate the background corrected LI, the average LI of the minus-UGT control plus-UDPGA wells was subtracted from the average LI of the minus-UDPGA reaction, and then this LI value was added to all the remaining LI of plus-UDPGA reactions. The inhibitory effects of test samples on the activities of UGTs were created with concentration-dependent inhibition response curves by logistic 3 or 4 parameter curve fit function of SigmaPlot program. The data were described as the mean \pm standard error of the mean $(\mathrm{SEM})(\mathrm{n}=2)$.

\section{Results}

\section{Anti-inflammatory effects in LPS-stimulated RAW 264.7 cells}

The inhibitory effects of YST, PJS and finasteride on the production of inflammatory mediators and cytokines in LPS-stimulated RAW 264.7 cells were investigated. YST inhibited the LPS-induced production of NO, $\mathrm{PGE}_{2}$ and IL-6 in RAW 264.7 cells in a dose-dependent manner (Fig. 1). The NO level was reduced to $56.25 \pm 1.02 \%$ of the level of LPS-treated cells by YST at a concentration of $400 \mu \mathrm{g} / \mathrm{mL}$, which is the maximum concentration without cytotoxicity in RAW 264.7 cells (Fig. 1A and supplementary Fig. 1). $\mathrm{PGE}_{2}$ production was strongly inhibited by YST; the $\mathrm{IC}_{50}$ was below 25 $\mu \mathrm{g} / \mathrm{mL}$, which is the minimum concentration to treat the cells (Fig 1B). Concerning IL-6 production, the $\mathrm{IC}_{50}$ value of YST was $104.21 \mu \mathrm{g} / \mathrm{mL}$ (Fig. 1C). PJS inhibited $\mathrm{NO}$ and $\mathrm{PGE}_{2}$ production in a dose-dependent manner, and the $\mathrm{IC}_{50}$ value of PJS on $\mathrm{PGE}_{2}$ inhibition was $106.15 \mu \mathrm{g} / \mathrm{mL}$ (Fig. 1A and $1 \mathrm{~B})$. The maximum inhibitory percentage of NO production was $22.50 \pm 5.77 \%$ at $100 \mu \mathrm{g} / \mathrm{mL}$ PJS compared to the LPS-treated cells (Fig. 1A). IL-6 levels were reduced in a dose-dependent manner at low concentrations (12.5 and $25 \mu$ $\mathrm{g} / \mathrm{mL}, \mathrm{p}<0.01)$ of PJS; however, the level of IL-6 gradually increased at over $50 \mu \mathrm{g} / \mathrm{mL}$ and finally became similar to the level of LPS-treated cells at $200 \mu \mathrm{g} / \mathrm{mL}$ (Fig. 1C). Finasteride, a typical medication to treat $\mathrm{BPH}$, inhibited $\mathrm{PGE}_{2}$ and IL-6 production in a dose-dependent manner. The $\mathrm{IC}_{50}$ values for $\mathrm{PGE}_{2}$ and IL-6 production were 11.54 and 30.90 $\mu \mathrm{M}$ finasteride (Fig. 1B and 1C). The NO level was significantly reduced at $40 \mu \mathrm{M}$ finasteride $(p<0.05)$, however, the percent inhibition was very low, $13.03 \pm 1.43 \%$ compared to the LPS-treated cells (Fig. 1A). There were no inhibitory effects on LPS-induced TNF- $\alpha$ production upon treatment 


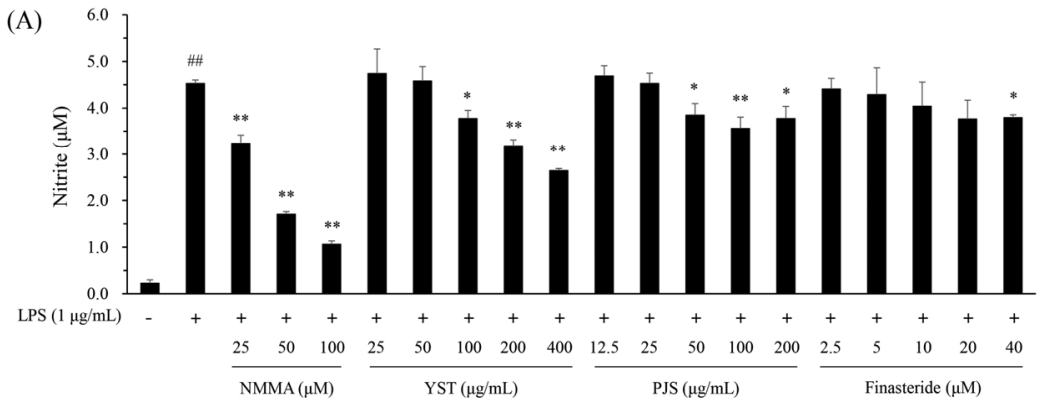

(B)

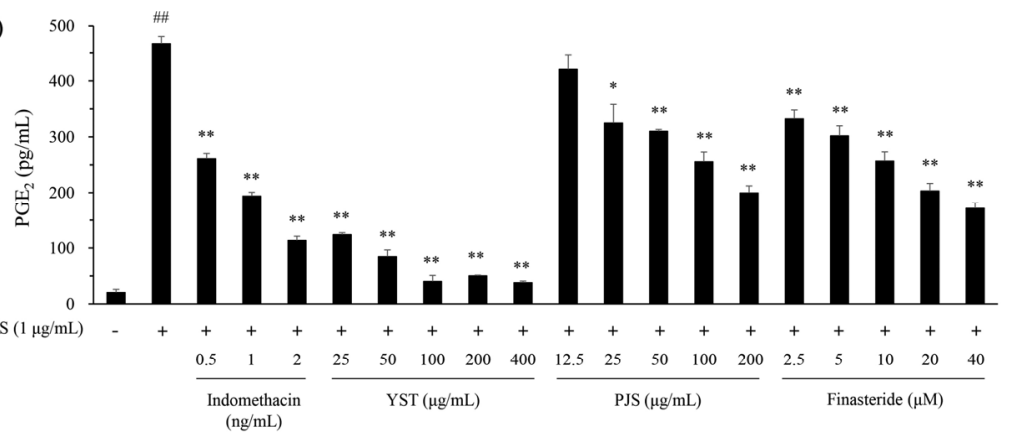

(C)
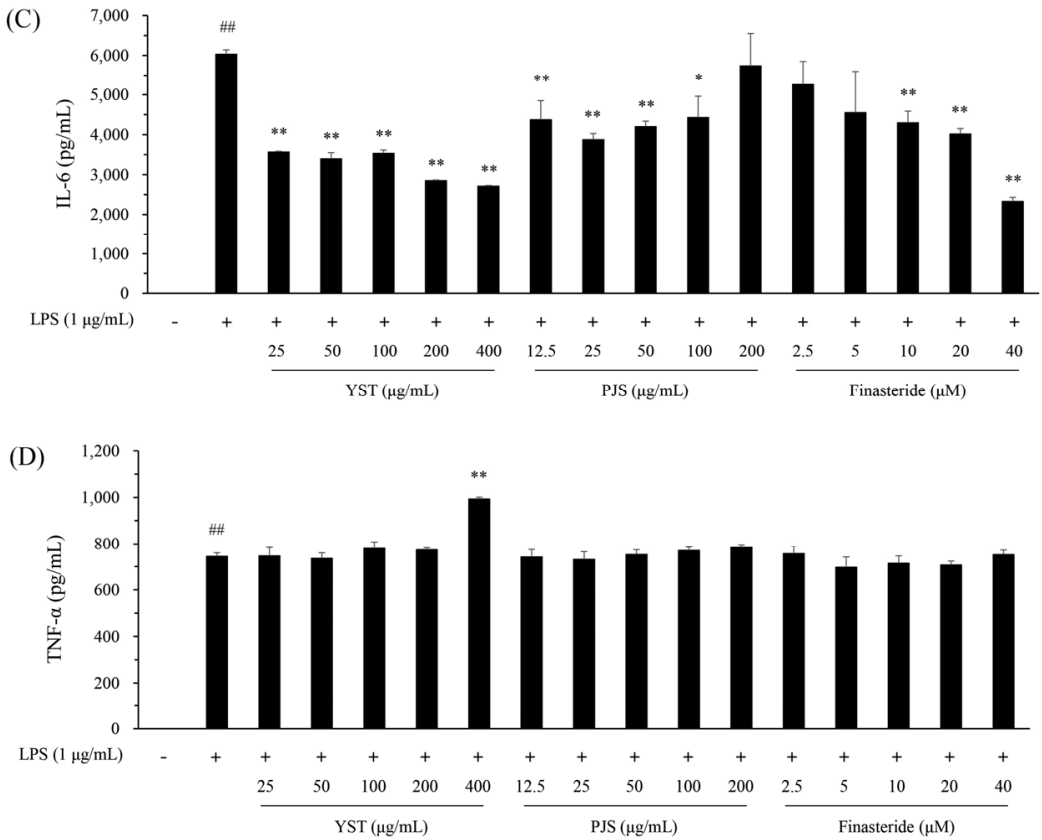

Fig. 1. Effects of Yongdamsagan-tang (YST) and Paljung-san (PJS) extracts and finasteride on LPS-induced inflammatory responses in RAW 264.7 cells. RAW 264.7 cells $\left(2.5 \times 10^{5}\right.$ cells/well, 48-well plate) were incubated with various concentrations of drugs in the presence or absence of LPS $(1 \mathrm{\mu g} / \mathrm{mL})$ for $24 \mathrm{~h}$. NO production was determined by a Griess reagent assay kit (A). The production of PGE $(B), I L-6$ (C), and TNF- $\alpha$ (D) were measured by ELISA, as described in the Materials and Methods. \#\#; P<0.01 compared to normal. ${ }^{*}$ and ${ }^{* *} ; p<0.05$ and P<0.01 compared to the LPS-treated control, respectively. 
of YST, PJS and finasteride in RAW 264.7 cells (Fig. 1D). The $\mathrm{IC}_{50}$ values of positive controls, NMMA and indomethacin, which inhibit LPS-stimulated $\mathrm{NO}$ and $\mathrm{PGE}_{2}$ production, were $35.28 \mu \mathrm{M}$ and $0.617 \mathrm{ng} / \mathrm{mL}$, respectively.

\section{Inhibitory effects on the activities of human drug metabolizing enzymes (DMEs)}

Change in enzyme activities caused by YST and PJS were measured on DMEs. YST inhibited the activities of 7 CYP450s and 3 UGTs in a dose-dependent manner (Fig. 2). The $\mathrm{IC}_{50}$ values of YST on UGT1A4 and UGT2B7 were 49.35 and $165.17 \mu \mathrm{g} / \mathrm{mL}$, respectively, whereas other enzymes were slightly inhibited, since $\mathrm{IC}_{50}$ values were over than $300 \mu \mathrm{g} / \mathrm{mL}$. The $\mathrm{IC}_{50}$ values of CYP1A2, CYP2C19 and CYP3A4 were 555.81, 601.62 and $720.74 \mu \mathrm{g} / \mathrm{mL}$, respectively (Table 3). However, the $\mathrm{IC}_{50}$ values of CYPB6, CYP2C9, CYP2D6 and CYP2E1 were could not be calculated because they were more than $1000 \mu \mathrm{g} / \mathrm{mL}$. The inhibitory effects of PJS were relatively strong compared to the effects of YST on DMEs. The 10 DMEs were inhibited by PJS in a dose-dependent manner (Fig. 2). There was relatively strong inhibition by PJS on CYP1A2 and CYP2C19 activities with $\mathrm{IC}_{50}$ values of 49.07 and $53.84 \mu$ $\mathrm{g} / \mathrm{mL}$, respectively. PJS was a moderate inhibitor of CYP2B6, CYP2C9, CYP2E1, CYP3A4 and UGT1A with $\mathrm{IC}_{50}$ values of $84.89,170.54,191.06$, 85.86 and $77.03 \mu \mathrm{g} / \mathrm{mL}$, respectively. PJS negligibly inhibited CYP2D6, UGT1A4 and UGT2B7 activities with their $\mathrm{IC}_{50}$ values being higher than $300 \mu \mathrm{g} / \mathrm{mL}$ (Table 3).

\section{Discussion}

The cause of BPH development in men has not been thoroughly elucidated; however, it is presumed that sex hormone changes caused by aging, such as increasing levels of DHT, which has higher affinity for the androgen receptor than testosterone; metabolic syndromes, including obesity and cardiovascular risk factors; and chronic prostatic inflammation $^{20-22)}$. Infiltration of inflammatory cells, including $\mathrm{T}$ and $\mathrm{B}$ lymphocytes, macrophages, and mast cells was in most TURP specimens from BPH patients was reported ${ }^{23,24)}$. Management methods for $\mathrm{BPH}$ are classified as follows: 1) watchful waiting, 2) medical treatments, including mono and combination drug therapy, 3) surgical treatments such as TURP and simple prostatectomy, and 4) device therapies such as transurethral microwave thermotherapy (TUMT), transurethral needle ablation (TUNA), urethral stent, and prostatic urethral lift ${ }^{22}$. A portion of patients are not only unsatisfied with the therapeutic efficacies of conventional medications but also have concerns regarding adverse effects. Herbal medicines have a long history of being used to treat several diseases, and might be considered safer than synthesized chemical drugs ${ }^{3}$. Monotherapy of herbal remedies and combination therapies with conventional medications in patients with BPH is increasingly being used ${ }^{25)}$. Therefore, the combination of finasteride, an inhibitor of $5 \alpha$-reductase, with herbal formulas, which have anti-inflammatory effects, may be more effective to treat $\mathrm{BPH}$. In the present study, anti-inflammatory activities of the herbal formulas YST and PJS and the drug finasteride were evaluated in LPS-stimulated 


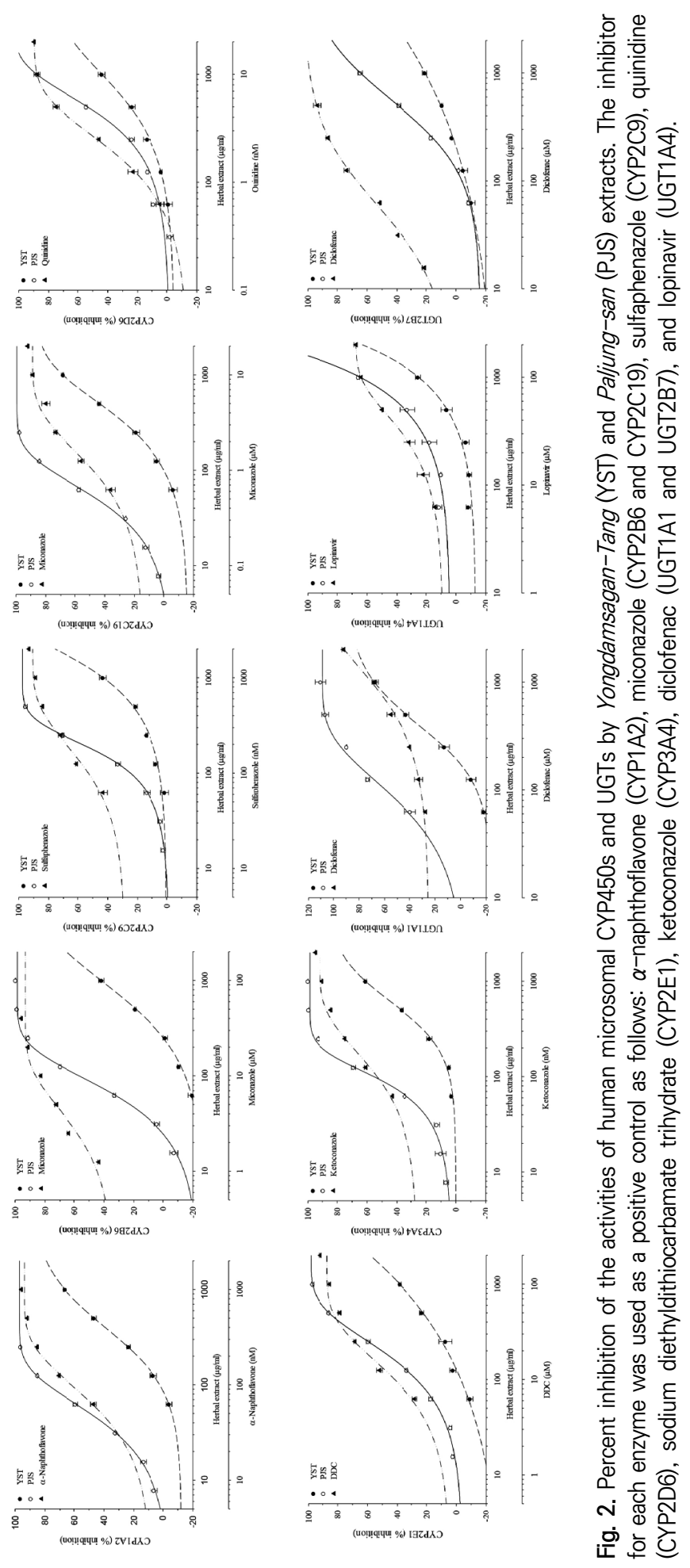


RAW 264.7 cells. The production of $\mathrm{NO}, \mathrm{PGE}_{2}$, and IL-6 were inhibited by treatment of YST, PJS, and finasteride. However, TNF- $\alpha$ was not inhibited by YST, PJS, and finasteride. Lim et al. have reported that YST inhibits NO and IL-6 production in LPS-stimulated RAW 264.7 cells, even though the composition of YST was slightly different from that in the present study ${ }^{26)}$.

Williams et al., reported that, as of 2002, approximately $75 \%$ of the top 200 drugs prescribed in the United States are eliminated by DMEs, that approximately $70 \%$ of these drugs are metabolized by the CYP450s (phase I DMEs), that approximately $15 \%$ of these drugs are metabolized by the UGTs (phase II DMEs) $^{27)}$. Treating chronic diseases with multiple drugs has increased because most chronic diseases develop with several complications. However, the use of multiple drugs increases the risk of side effects such as reducing the efficacy and increasing the toxicity of drugs by drug-drug interactions, herb-drug interactions, and drug-food interactions ${ }^{28)}$. Guidelines for drug-drug interaction
(DDI) research are presented in each country, such as the US food and drug administration (FDA) and the European medicines agency (EMA) guidelines ${ }^{29)}$, but there is still no standard method for herb-drug interaction (HDI) research, and HDI-related studies are lacked compared to DDI. Assessing the influence of herbal medicines on the activity of DMEs in an in vitro system is a basic tool to predict a potential of $\mathrm{HDI}^{30}$.

In the present study, the influence of the herbal formulas YST and PJS, which have been used to treat $\mathrm{BPH}$, on activities of seven CYP450s and three UGTs from human microsomes were assayed to predict herbal-drug interactions. YST inhibited the activities of all enzymes, however the $\mathrm{IC}_{50}$ values for the enzymes, except for UGT1A4, were higher than $100 \mu \mathrm{g} / \mathrm{mL}$, a concentration that might not influence the metabolism of other drugs. The activity of UGT1A4 was inhibited with an $\mathrm{IC}_{50}$ value of $49.35 \mu \mathrm{g} / \mathrm{mL}$ by YST. PJS inhibited the activities of CYP1A2, CYP2B6, CYP2C19, CYP3A4, and UGT1A1 with $\mathrm{IC}_{50}$

Table 3. $\mathrm{IC}_{50}$ Values of Yongdamsagan-tang (YST) and Paljung-san (PJS) Extracts on the Activities of Human Microsomal CYP450s and UGTs

\begin{tabular}{cccll}
\hline $\begin{array}{c}\text { Drug metabolizing } \\
\text { enzyme }\end{array}$ & $\begin{array}{c}\text { YST } \\
(\mu \mathrm{g} / \mathrm{mL})\end{array}$ & $\begin{array}{c}\text { PJS } \\
(\mu \mathrm{g} / \mathrm{mL})\end{array}$ & Positive control & \\
\hline CYP1A2 & 555.81 & 49.07 & 69.54 & $\alpha$-Naphthoflavone $(\mathrm{nM})$ \\
CYP2B6 & $>1000$ & 84.89 & 1.55 & Miconazole $(\mu \mathrm{M})$ \\
CYP2C9 & $>1000$ & 170.54 & 80.85 & Sulfaphenazole $(\mathrm{nM})$ \\
CYP2C19 & 601.62 & 53.84 & 0.98 & Miconazole $(\mu \mathrm{M})$ \\
CYP2D6 & $>1000$ & 462.44 & 2.61 & Quinidine $(\mathrm{nM})$ \\
CYP2E1 & $>1000$ & 191.06 & 11.73 & DDC $(\mu \mathrm{M})$ \\
CYP3A4 & 720.74 & 85.86 & 80.27 & Ketoconazole $(\mathrm{nM})$ \\
UGT1A1 & 449.74 & 77.03 & 442.66 & Diclofenac $(\mu \mathrm{M})$ \\
UGT1A4 & 49.35 & $>1000$ & 744.03 & Lopinavir $(\mu \mathrm{M})$ \\
UGT2B7 & 165.17 & $>1000$ & 669.65 & Diclofenac $(\mu \mathrm{M})$ \\
\hline
\end{tabular}

DDC: sodium diethyldithiocarbamate trihydrate 
values below $100 \mu \mathrm{g} / \mathrm{mL}$. Finasteride is excreted via two metabolic pathways mediated by as follows; 1) CYP3A4 and UGT1A4, and 2) CYP3A4 and UGT1A3. Finasteride is converted to $\omega$-hydroxyfinasteride and hydroxyfinasteride glucuronide through the first pathway, and converted to finasteride- $\omega$-oic acid and finasteride carboxylic acid glucuronide via the other pathway, respectively ${ }^{31)}$. Finasteride does not appear to influence CYP450-mediated drug metabolism. Although PJS and YST inhibited the activities of CYP3A4 and UGT1A4, respectively, they might not influence the metabolism of finasteride because the $\mathrm{IC}_{50}$ values of herbal formulas on drug metabolizing enzymes are too high to affect the metabolism. Our results suggest that the combination with finasteride and YST or PJS might not influence drug metabolism of each other and we expected there to be synergistic effects to treat $\mathrm{BPH}$.

\section{Conflict of interest}

The authors declare that there is no conflict of interest.

\section{Acknowledgments}

This research was supported by grants of the 'Construction of Scientific Evidence for Herbal Medicine Formulas (K17251)' and 'Construction of Safety and Efficacy for Traditional Herbal Prescriptions of Medicinal Institution (KSN2013310)' projects from the Korea Institute of Oriental Medicine (KIOM), Republic of Korea.

\section{References}

1. Brasure, M., MacDonald, R., Dahm, P., Olson, C. M., Nelson, V. A., Fink, H. A., et al. (2016). Newer Medications for Lower Urinary Tract Symptoms Attributed to Benign Prostatic Hyperplasia: A Review. Rockville (MD): Agency for Healthcare Research and Quality (US). http://www.ncbi.nlm.nih.gov/ books/NBK368444/

2. Elkelany, O. O., Owen, R. C., \& Kim, E. D. (2015). Combination of tadalafil and finasteride for improving the symptoms of benign prostatic hyperplasia: critical appraisal and patient focus. Therapeutics and Clinical Risk Management, 11, 507-513. https://doi.org/10. 2147/TCRM.S80353

3. Azimi, H., Khakshur, A. A., Aghdasi, I., Fallah-Tafti, M., \& Abdollahi, M. (2012). A review of animal and human studies for management of benign prostatic hyperplasia with natural products: perspective of new pharmacological agents. Inflammation and Allergy Drug Targets, 11(3), 207-221. https://doi.org/10.2174/187152812800392715

4. Yuan, H., Ma, Q., Ye, L., \& Piao. G. (2016). The traditional medicine and modern medicine from natural products. Molecules, 21(5): 559. https://doi.org/10.3390/molecules21050559

5. Chen, J., Li, P., Sun, Z., Wang, C., Wang, T., \& Wang, B. (2015). Five methods of syndrome differentiation and treatment for benign prostatic hyperplasia. Journal of Practical Traditional Chinese Internal Medicine, 29(11), 67-69. https://doi.org/10.13729/j.issn. 1671-7813.2015.11.32 
6. Lee, T. Y. \& Chang, H. H. (2010). Longdan Xiegan Tang has immunomodulatory effects on $\mathrm{CD} 4{ }^{+} \mathrm{CD} 25^{+} \mathrm{T}$ cells and attenuates pathological signs in MRL/lpr mice. International Journal of Molecular Medicine, 25(5), 677-85. https://doi.org/10.3892/ijmm_00000391

7. Kim, J. J., Kim, H. J., An, B. K., Hong, W. S., Kim, W. H., Lee, S. I., et al. (1978). Studies on the therapeutics for liver diseases in herb remedies (VI): Experimental study on the effect on Ryongdamsakan-Tang. Kyung Hee University Oriental Medical Journal, 1, 31-5.

8. Seo, M. S., Jin, Y. S., \& Jung, K. M. (1991). Effects of Yongdamsagantang and Yongdamsagantang -gamibang on the anti-allergic effect in rats and mice. Journal of Korean Oriental Pediatrics, 5, 15-27. https://www.koreascience.or.kr/article/ JAKO199104637300724.pdf

9. Furuya, S. \& Takahashi, K. (2003). Clinincal investigation of the efficacy of Ryutan-shakan -to in the treatment of postoperative pain and discomfort following transurethral resection of the prostate. Kampo Medicine, 54(1), 183189. https://www.jstage.jst.go.jp/article/kampomed 1982/54/1/54_1_183/_pdf/-char/ja

10. Moriyama, M. T., Ikeda, R., \& Suzuki, K. (2003). Ryutan-shakan-to for the treatment of urination difficulty. Journal of Traditional Medicine, 20(5), 230-234.

11. Song, M. K., Park, S. H., Kang, J. S., Ahn, Y. M., Ahn, S. Y., Kim, Y. O., et al. (2010). Report of four cases of Paljung-san on lower urinary tract symptoms in patients with benign prostatic hyperplasia. Journal of Korean Oriental Medicine, 31(1), 153-161.
https://www.koreascience.or.kr/article/JAKO2 01021147394355.pdf

12. Lee, S. W., Na, H. Y., Yoo, J. H., Ahn, Y. M., Ahn, S. Y., Kin, Y. O., et al. (2015). Effects of Paljeong-san on chronic nonbacterial prostatitis induced in rats by estradiol. Journal of Internal Korean Medicine, 36(2), 180-188. https://www.koreascience.or.kr/article/ JAKO201525850332466.pdf

13. Tong, Y. \& Zhou, R. Y. (2020). Review of the roles and interaction of androgen and inflammation in benign prostatic hyperplasia. Mediators of Inflammation, 2020:7958316. https://doi.org/10.1155/2020/7958316

14. Krušlin, B., Tomas, D., Džombeta, T., Milković-Periša, M., \& Ulamec, M. (2017). Inflammation in prostatic hyperplasia and carcinoma-basic scientific approach. Frontiers in Oncology, 7, 77. https://doi.org/10.3389/ fonc.2017.00077

15. Park, E., Lee, M. Y., Jeon, W. Y., Lee, N., Seo, C. S., \& Shin, H. K. (2016). Inhibitory effect of Yongdamsagan-Tang water extract, a traditional herbal formula, on testosterone -induced benign prostatic hyperplasia in rats. Evidence Based Complement and Alternative Medicine, 2016, 1428923. https://doi.org/ $10.1155 / 2016 / 1428923$

16. Park, E., Lee, M. Y., Seo, C. S., Jeon, W. Y., \& Shin, H. K. (2017). Yongdamsagan-tang, a traditional herbal formula, inhibits cell growth through the suppression of proliferation and inflammation in benign prostatic hyperplasia epithelial-1 cells. Journal of Ethnopharmacology, 209, 230-235. https://doi.org/10.1016/j.jep.2017. 08.002 
17. Park, E., Lee, M. Y., Jeon, W. Y., Seo, C. S., You, S., \& Shin, H. K. (2018). Paljung-San, a traditional herbal medicine, attenuates benign prostatic hyperplasia in vitro and in vivo. Journal of Ethnopharmacology, 218, 109-115. https://doi.org/10.1016/j.jep.2018.02.037

18. Agbabiaka, T. B., Wider, B., Watson, L. K., \& Goodman, C. (2017). Concurrent use of prescription drugs and herbal medicinal products in older adults: A systematic review. Drugs Aging, 34, 891-905. https://doi.org/ 10.1007/s40266-017-0501-7

19. Amitani, M., Amitani, H., Sloan, R. A., Suzuki, H., Sameshima, N., Asakawa, A., et al. (2015). The translational aspect of complementary and alternative medicine for cancer with particular emphasis on Kampo. Frontiers in Pharmacology, 6, 150. https://doi.org/10.3389/fphar.2015.00150

20. Vuichoud, C. \& Loughlin, K. R. (2015). Benign prostatic hyperplasia: epidemiology, economics and evaluation. The Canadian Journal of Urology, 22(Suppl 1), 1-6. https://www.canjurol.com/html/free-articles/J UV22I5S1F_06_DrLoughlin.pdf

21. Olesovsky, C. \& Kapoor, A. (2016). Evidence for the efficacy and safety of tadalafil and finasteride in combination for the treatment of lower urinary tract symptoms and erectile dysfunction in men with benign prostatic hyperplasia. Therapeutic Advances in Urology, 8(4), 257-271. https://doi.org/10.1177/175628 7216650132

22. Kim, E. H., Larson, J. A., \& Andriole, G. L. (2016). Management of Benign Prostatic Hyperplasia. Annual Review of Medicine,
67, 137-151. https://doi.org/10.1146/annurev -med-063014-123902

23. Di Silverio, F., Bosman, C., Salvatori, M., Albanesi, L., Proietti Pannunzi, L., Ciccariello, M., et al. (2005). Combination therapy with rofecoxib and finasteride in the treatment of men with lower urinary tract symptoms (LUTS) and benign prostatic hyperplasia (BPH). European Urology, 47(1), 72-79. https://doi.org/10.1016/j.eururo.2004.08.024

24. Kramer, G., Mitteregger, D., \& Marberger, M. (2007). Is benign prostatic hyperplasia $(\mathrm{BPH})$ an immune inflammatory disease? European Urology, 51(5), 1202-1216. https://doi.org/10.1016/j.eururo.2006.12.011

25. Ma, C. H., Lin, W. L., Lui, S. L., Cai, X. Y., Wong, V. T., Ziea, E., et al. (2013). Efficacy and safety of Chinese herbal medicine for benign prostatic hyperplasia: systemic review of randomized controlled trials. Asian Journal of Andrology, 15(4), 471-482. https://doi.org/ 10.1038/aja.2012.173

26. Lim, J. H., Lee, J. R., Kim, S. C., \& Jee, S. Y. (2007). Inhibitory effect of Yongdamsagantang water extract in IL-6 and nitric oxide production in lipopolysaccharide-activated RAW264.7 cells. Oriental Pharmacy and Experimental Medicine, 7(3), 321-329. https://doi.org/10.3742/OPEM.2007.7.3.321

27. Williams, J. A., Hyland, R., Jones, B. C., Smith, D. A., Hurst, S., Goosen, T.C., et al. (2004). Drug-drug interactions for UDP -glucuronosyltransferase substrates: a pharmacokinetic explanation for typically observed low exposure (AUCi/AUC) ratios. Drug Metabolism and Disposition, 32(11), 
1201-1208. https://doi.org/10.1124/dmd.104.000794

28. Huang, S. M. \& Lesko, L.J. (2004). Drug-drug, drug-dietary supplement, and drug-citrus fruit and other food interactions: what have we learned? Journal of Clinical Pharmacology, 44(6), 559-569. https://doi.org/10.1177/0091 270004265367

29. Prueksaritanont, T., Chu, X., Gibson, C., Cui, D., Yee, K. L., Ballard, J., et al. (2013). Drug-drug interaction studies: regulatory guidance and an industry perspective. The AAPS Journal, 15(3), 629-645. https://doi.org/ 10.1208/s12248-013-9470-x

30. Grimstein, M. \& Huang, S.M. (2018). A regulatory science viewpoint on botanical-drug interactions. Journal of Food and Drug Analysis, 26(2S), S12-S25. https://doi.org/ 10.1016/j.jfda.2018.01.013

31. Hulin-Curtis, S. L., Petit, D., Figg, W. D., Hsing, A. W., \& Reichardt, J. K. (2010). Finasteride metabolism and pharmacogenetics: new approaches to personalized prevention of prostate cancer. Future Oncology, 6(12), 1897-1913. https://doi.org/10.2217/fon.10.149

\section{ORCID}

Hyekyung Ha https://orcid.org/0000-0002-7326-6366 Seong Eun Jin https://orcid.org/0000-0002-9224-0735

Chang-Seob Seo https://orcid.org/0000-0002-8156-446X

Hyeun-kyoo Shin https://orcid.org/0000-0003-2319-6678 
(A)

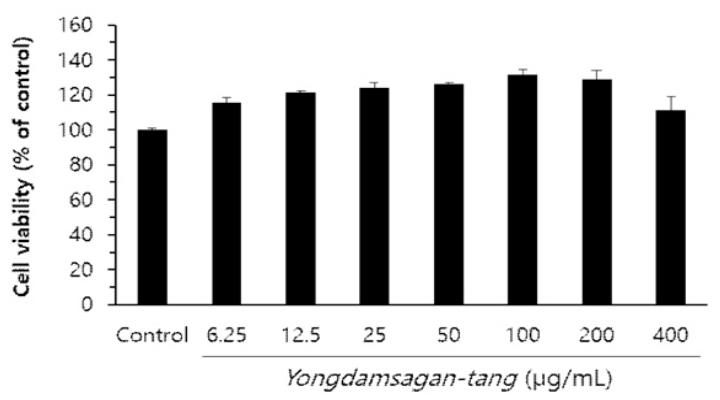

(B)

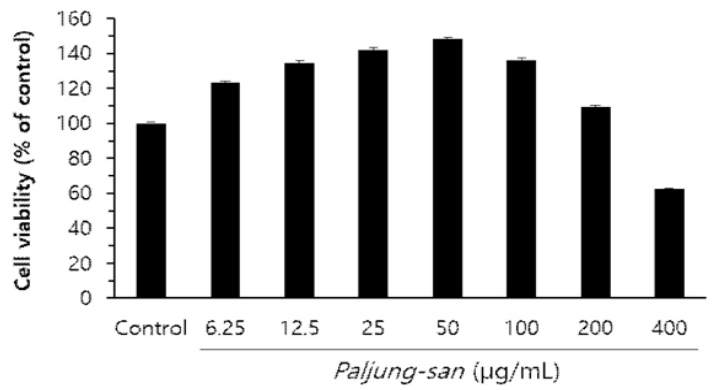

(C)

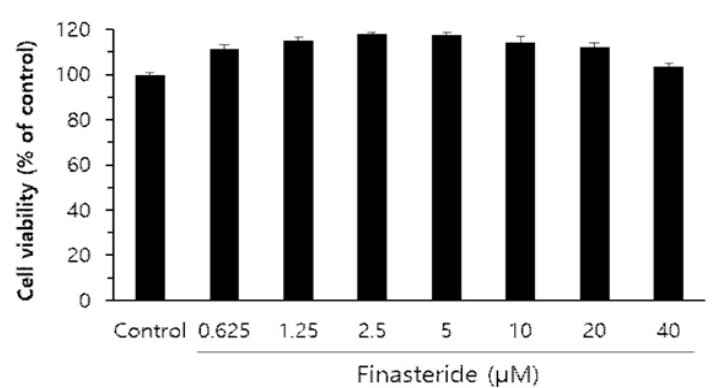

Supplementary Fig. 1. Cytotoxicity of (A), Paljung-san (B), and finasteride (C) in RAW 264.7 cells. The cells were treated with various concentrations of herbal formula extracts and finasteride for $24 \mathrm{~h}$. Cell Counting Kit-8 reagent was added and incubated for $4 \mathrm{~h}$. The absorbance of each well was measured at $450 \mathrm{~nm}$ and the percentages of viable cells were calculated. The values were expressed as mean $\pm \operatorname{SEM}(n=4)$. 